\title{
Note from the Editorial Team
}

\section{Dear readers,}

You are holding the first fully open access issue of Science \& Technology Studies. A few words about how this came to be, are in order.

Since Science \& Technology Studies started as the house journal of EASST (European Society for the Study of Science and Technology), it has had an embargo on its most recent issue that was provided as a benefit to members of EASST and FSSTS (Finnish Society for Science and Technology Studies) and other paying subscribers. During 2016, however, EASST and FSSTS councils deliberated this and decided to drop the embargo in favour of open access. During these debates, the councils considered the value of the journal as a member benefit against the opportunity of creating a flagship free-of-cost, open access STS journal that is also independent of commercial publishing houses. The councils discussed who they represent - the paid members (holding on to the idea of having a journal accessible through membership), or STS as a whole through open access to all.

The journal editorial team, EASST and FSSTS are pleased to announce that the journal will now become available to everyone (including a planned 'online first' pre-publication repository to get papers out ahead of their official publication). The journal appreciates the vision of councils -open access publication is possible thanks to the financial support from EASST.

Further announcements from the journal include welcoming two new editors Sarah de Rijcke and Alexandre Mallard, and Editorial Assistant Heta Tarkkala. Sampsa Hyysalo, on the other hand, a long lasting editor of the journal, is stepping aside after a decade in the editorial team and as the coordinating editor. With huge appreciation, we want to thank Sampsa for all his efforts in developing the journal to where it is now.

The review section is also undergoing changes. Our book review editors wish to confirm our recent expansion of the formats we are interested in covering the reviews section. Recognising that our reading and writing of texts as STS scholars is one end of a continuum, we have began to include exhibitions and other performative events in our remit. In our previous issue for example, we included a review of the recent museum exhibition Reset Modernity! at ZKM by Endre Dányi and Michaela Spencer (see http:// sciencetechnologystudies.journal.fi/article/ view/59527).

Our review editors seek inputs from readers for upcoming reviews - please contact either Brit Winthereik or Helen Verran if you'd be interested in reviewing any of the following:

- 2017 is the $25^{\text {th }}$ anniversary of the publication of Science as Practice and Culture, Andrew Pickering (ed.) by University of Chicago Press. Reviewing it in Contemporary Sociology in 1993, Malcolm Ashmore began his review this way: "This volume... has a mission encapsulated in the following slogan or rallying cry: sociology of knowledge (SSK) is dead; long live sociology of scientific practice!" We are asking for an early career researcher to review this text twentyfive years later. How does it look now? Is it an STS classic?

- Last year the whopping $4^{\text {th }}$ edition of the Science and Technology Studies Handbook was 
published by MIT Press. It has 36 chapters each available as a separate text. We are asking our readers for expressions of interest in reviewing self-designed clusters of up to six chapters. The idea is that we include a review of selected chapters of this text in each of four successive issues across 2017-8. We are then, looking for up to six reviewers who will select up to six chapters from the book and review them as a cluster. We will arrange for the book to be sent to you from the publisher as a pdf. Unfortunately, those who have published chapters in the Handbook are not eligible. Identify your chapters and tell us when your review will be available.

- At the end of February Amsterdam's 'Sonic Acts' will stage their annual festival "The Noise of Being," featuring STS scholars as speakers. If you plan to attend and can write a review of this event to be published in the second edition of S\&TS in 2017, please email Brit or Helen. http://sonicacts.com/2017/festival/ sonic-acts-at-de-brakke-grond

Finally, as ever, we welcome new submissions from scholars across Europe and elsewhere research papers and review articles, discussion papers and book or exhibition reviews as well as special issue proposals - we look forward working with you. This work would not be possible without our reviewers so most importantly, we want to express our gratitude to our reviewers whose contributions are vital to the success and quality of the journal. Thank you.

On behalf of the editorial team and best wishes,

Salla Sariola

Coordinating editor

Science \& Technology Studies 